\title{
Making as a Pathway to Foster Joyful Engagement and Creativity in Learning
}

\author{
Michail N. Giannakos ${ }^{1}$, Monica Divitini ${ }^{1}$, Ole Sejer Iversen ${ }^{2}$ and Pavlos Koulouris ${ }^{3}$ \\ ${ }^{1}$ Norwegian University of Science and Technology (NTNU), Trondheim, Norway \\ \{michailg, divitini\}@idi.ntnu.no \\ ${ }^{2}$ Participatory IT Center, Aarhus University, Aarhus, Denmark \\ oiversen@cs.au.dk \\ ${ }^{3}$ Ellinogermaniki Agogi, Athens, Greece \\ pkoulouriseea.gr
}

\begin{abstract}
The International Workshop of Making as a Pathway to Foster Joyful Engagement and Creativity in Learning (Make2Learn) aims to discuss the introduction of creative and joyful production of artifacts in the learning processes. A variety of environments have been developed by researchers to introduce making principles to young students. Making principles enable them foster cocreativity and joy in learning processes and construct knowledge. By involving students in the design decisions they begin to develop technological fluency and the needed competences, in a joyful way. Make2Learn aims to bring together international researchers, educators, designers, and makers for the exploration of making principles towards the acquisition of 21 st Century learning competences, by employing the state of the art aspects of entertainment technologies, new media, gaming, robotics, toys and applications. The main objective is to build a research community around this topical area. In particular, Make2Learn aims to develop a critical discussion about the well-established practices and entertainment technologies of the maker movement, and expected outcomes of putting them into practice under different spaces such as Hackerspaces, Makerspaces, TechShops, FabLabs etc. This will allow us to better understand and improve the value of Maker philosophy and the role of entertainment technologies to support teaching and learning.
\end{abstract}

Keywords: Maker movement, entertainment technologies, creativity, knowledge construction, technological fluency, constructionist

\section{BACKGROUND}

Digital artifacts that enable people to exchange, create, and distribute information have, in the past couple of decades, profoundly reshaped the way we work and live [8]. The creative production of digital artifacts and use of entertainment technologies in learning activities has been linked to teaching new computer and design literacy skills [2]. Common inspiration is the work of Papert [7] that stresses the importance of creating a 'felicitous' environment to facilitate learning. The idea here is that the 
students benefit from being happy and in a carefree and creative environment. In accordance with Papert, Csikszentmihalyi's [4] research has exhibited that students' motivation is highly predictive of achievement; however, educational systems neglect creative and joyful aspects on learning activities. Educational programmes focus on recall and reproduction abilities instead of emphasizing the development of problem solving, creative thinking and decision-making abilities.

Digital artifacts have the potential to make the symbolic and abstract manipulations involved in creative procedures more concrete and manageable for young students [3]. For example, artifacts allow students to learn by iteratively testing, rebuilding their designs and working collaboratively. The interactions between the young students and the artifacts in creative and joyful activities are vital [5]. During the past decade, we have seen an increased appearance of environments and community spaces offering diverse opportunities for young students to facilitate learning through construction. Environments like Scratch, Alice and Storytelling Alice and spaces like Hackerspaces, Makerspaces, TechShops, and FabLabs have allowed researchers to empirically investigate the potential benefits of the maker movement towards the acquisition of 21st Century learning competences. Collecting and discussing around those advances will allow us to formulate better understanding of several technical and practical aspects that could be valuable in designing effective making activities to foster joyful engagement and creativity in learning.

\section{OBJECTIVES}

The advances of digital environments, entertainment technologies, manufacturing equipment and community spaces offer diverse opportunities for making practices to facilitate learning, especially when supported by engaging and joyful entertainment technologies and designed in an appropriate pedagogical manner. From current research, it is difficult to tell what aspects of environments, engaging-entertainment technologies, applications, equipment and practices can have a positive impact.

The current drive in many countries to teach design and technology competences to all has potential to empower and support making as a creative, joyful and problemsolving tasks. However, there are a number of challenges in ensuring that procedures, tools and environments, embody appropriate progression and engender motivation and joyful. This workshop will attempt to address these key research challenges.

One of our main objectives is to bring together researchers, educators, designers who are interested for the exploration of making principles and supportive entertainment technologies towards the acquisition of 21 st Century learning competences. Make2Learn aims to provide an environment where participants will get opportunities to: develop their research skills; increase their knowledge base; collaborate with others in their own and complementary research areas; and discuss their own work. 


\section{MAKING INSTRUMENTS: TOOLS, KITS AND SPACES TO SUPPORT CREATIVITY}

Cultures of making-like, social practices of hacking, DIY, and craft-rise in prominence, and design researchers have taken note, because of their implications for sustainability, democratization, and alternative models of innovation, design, participation, and education [1]. Designing tools, kits and spaces to support constructionism and creativity via new modalities, not only leverages more authentic connections to engagement but also extends learning opportunities as youth align computing, engineering and interaction design.

Tools to support creativity can be described as tools that enable people to express themselves creatively and to develop as creative and critical thinkers [8]. Tools, like computational systems and environments that people can use to generate, modify, interact and play with, and/or share artifacts such as programs, diagrams, artifacts, installations, designs, images, and music; these tools can help us to enhance people's creativity if designed and applied properly. Drawn from a large pool of diverse studies, Shneiderman et al. [10] have defined twelve "design guidelines" (called also patterns) to guide the development of creativity support tools:

1. Support exploration,

2. Low threshold, high ceiling, and wide walls

3. Support many paths and many styles,

4. Support collaboration,

5. Support open interchange,

6. Make it as simple as possible — and maybe even simpler,

7. Choose black boxes carefully,

8. Invent things that you would want to use yourself,

9. Balance user suggestions with observation and participatory processes,

10. Iterate, iterate - then iterate again,

11. Design for designers,

12. Evaluate your tools.

These principles are distinguished from other user interface principles because they emphasize on easy exploration, rapid experimentation, and fortuitous combinations that lead to innovations [10]. These twelve principles allow designers not only to develop successful tools to support creativity but also to improve different commercial products like programming environments, design, brainstorming, composite music etc.

Many types of physical and digital products as well as toys can offer learning experiences that foster students' creativity and $21^{\text {st }}$ century skills. Related tool categories include diverse new media, smart environments, physical and digital games, robotics, toys and so forth. Various types of construction kits are also often reinforce joyfulness, creativity, engagement and learning. However, most of the available construc- 
tion kits are focusing on a very specific set of skills and competences, and support a non-systematic ad-hoc learning model.

Creativity is often supported by physical products as well as tangible technologies. For instance in OurToys [6], students build their own digital game/story with physical objects; this raised their awareness for technology, explored their design and development boundaries as well as increase their collaboration while learning and playing through the making process. Another interesting mean to enhance creativity is designing and developing wearable products. For instance, designing wearable controllers, interfaces and boards where young programmers can manipulate objects not only on the screen but also in the physical world provide a compelling application of creative learning [2].

In addition to available toolkits, technologies and environments for creative learning, there are some dedicated spaces to introduce students to the making movement principles, such as Hackerspaces, Makerspaces, TechShops, FabLabs etc. On the top of these spaces there are also events like, Lego League Junior and Maker Faires. But again, most of the available events and spaces are focusing on a very specific set of skills and competences with an ad-hoc organization/participation.

\section{CONCLUSIONS AND THE WAY AHEAD}

The advances of digital environments, technologies, manufacturing equipment and community spaces offer diverse opportunities for making practices to facilitate learning, especially when supported by engaging and joyful entertainment technologies and designed in an appropriate pedagogical manner. From current research, it is difficult to tell what aspects of environments, technologies, applications, equipment and practices can have a positive impact.

The current drive in many countries to teach $21^{\text {st }}$ century skills to all has potential to empower and support making as a creative, joyful, problem-solving and critical thinking tasks. However, there are a number of challenges in ensuring that procedures, tools and environments, embody appropriate progression and engender motivation and joyful.

To explore the future of technologies, tools, and various spaces to foster engagement and creativity in learning, we seek to promote interest in well-established tools and practices of the maker movement, and expected outcomes of putting them into practice under different spaces such as Hackerspaces, Makerspaces, TechShops, FabLabs etc. This will allow us to better understand and improve the value of Maker philosophy as well as to accelerate the process of disciplinary convergence. We aspire to bridge computer science, design, $\mathrm{HCI}$ and related disciplines to encourage ambitious research projects that could yield potent tools for many students to use. This workshop is implemented with an aim to collect high quality studies around this topical area, to envision what the next generation of technologies, environments, spaces and practices might look like. In particular, future work need to: 
1. Accelerate research on Maker Movement by proposing ways to create greater interest and synergies among researchers, educators, students, policymakers, and industrial developers,

2. Promote rigorous multidimensional and multidisciplinary methods and implement rigorous experimentation strategies and metrics for in-depth longitudinal case studies,

3. Design tools, kits and spaces for individuals to promote "low floor" (easy to get started) and a "high ceiling" (opportunities to create increasingly complex projects over time) opportunities for young students.

\section{Acknowledgments}

We would like to thank the workshop Program Committee members for contributing to the success of Make2Learn as well as the workshop and conference chairs for their constructive comments and their helpful assistance during the preparation and throughout the workshop.

\section{References}

1. Bardzell, J., Bardzell, S., \& Toombs, A.: now that's definitely a proper hack: self-made tools in hackerspaces. In Proc. CHI '14, ACM Press, 473-476 (2014)

2. Buechley, L., Eisenberg, M., Catchen, J. and Crockett, A.: The LilyPad Arduino: Using Computational Textiles to Investigate Engagement, Aesthetics, and Diversity in Computer Science Education. In Proc. CHI '08, ACM Press, 423-432 (2008)

3. Cassell, J.: Towards a Model of Technology and Literacy Development: Story Listening Systems, Journal of Applied Developmental Psychology 25(1), 75-105 (2004)

4. Csikszentmihalyi, M.: Creativity: Flow and the Psychology of Discovery and Invention. Harper Collins, (1996).

5. Giannakos, M. N., \& Jaccheri, L.: What motivates children to become creators of digital enriched artifacts?. In Proc. C\&C 2013, ACM Press, 104-113 (2013)

6. Giannakos, M. N., \& Jaccheri, L.: Code Your Own Game: The Case of Children with Hearing Impairments. Entrtainment Computing - ICEC 2014. Springer, 108-116 (2014)

7. Papert, S.: Mindstorms: Children, Computers, and Powerful Ideas. Basic Books New York, NY (1980)

8. Resnick, M. et al.: Design Principles for Tools to Support Creative Thinking. Technical Report: NSF Workshop Report on Creativity Support Tools. Washington, DC (2005)

9. Ryokai, K., Lee, M. J., and Breitbart, J. M.: Children's storytelling and programming with robotic characters. In Proc. C\&C 2009, ACM Press, 19-28 (2009)

10. Shneiderman, B., et al.: Creativity support tools: Report from a US National Science Foundation sponsored workshop. International Journal of Human-Computer Interaction, 20(2), 61-77 (2006) 